Conference Article

\title{
Dissimilar Effects of World News Announcements on Euro/Dollar/Yen Exchange Rates: An Econophysics Approach
}

\author{
David Matesanz ${ }^{1}$ and Guillermo J. Ortega ${ }^{2, *}$ \\ ${ }^{\prime}$ Applied Economics Department, University of Oviedo, Avda. Cristo s/n, 33006, Oviedo, Spain \\ ${ }^{2}$ Science and Technology Department, National University of Quilmes and CONICET, R. S. Peña 352, B1876BXD, Bernal, Argentina
}

\begin{abstract}
This paper revisits the issue of the influence of macro-economic announcements over the exchange rates volatility, but from a different perspective as it is the usual in the econometric literature. By quantifying the impact of world-wide macroeconomic information published in the economic calendar in several recent years we were able to construct long events' time series with the objective to test whether they influence exchange rate volatilities in several currencies. In order to do that, Granger causality test was employed by using a computational approach. Our results show that announcements from U.S.A are, by far, the most important influence over the three spot forex quotes, Euro/Dollar, Euro/Yen and Dollar/Yen. The method proposed here opens the door to address several open questions until now.
\end{abstract}

Keywords: Intraday data, Macroeconomic announcements, Exchange rates, Granger Causality, Surrogate data.

\section{Introduction}

The issue whether, and to what extent, macro-economic announcements influence exchange rates movements has received much attention in recent years [1-11]. The basic question in this issue is how news about macro-economic (fundamentals) announcements is incorporated into asset prices. Market efficiency theory [12] suggests that only unexpected relevant information coming from news announcements should influence current exchange rates, but convincing evidence that fundamentals may have a predictive value for these kind of assets has remained elusive until now.

Earlier empirical evidence has used either time series analysis models or regression analysis where empirical validation employed at most daily data. The results of these contributions to the study of the influence of fundamentals on exchange prices are non-conclusive and to some extent controversial. While some influential papers have suggested that prices and fundamentals are importantly disconnected [2] especially in the short run [3] other earlier papers have suggested on the contrary a close connection between fundamentals announcements and asset prices [4-6].

In the last decades the availability of extremely high frequency data has permitted important innovations in the empirical studies that allowed for the analysis of the very short run influence of news announcements on exchange prices. Most of this empirical literature has focused on the

*E-mail address: agetro.ortega@gmail.com ISSN: 1791-2377 @ 2015 Kavala Institute of Technology. All rights reserved. effects of news on asset return volatility [7-11]. General conclusions coming from this literature reveals that news clearly affects exchange rate volatility and these effects are very short lived. Another strand of the empirical literature has directly focused instead on the effects of news on returns themselves or exchange rate conditional means as opposed to conditional variances $[13,14]$. Again these studies report a robust link between macroeconomic news announcements to jumps in exchange rates. Moreover, jumps occur in the very short time after news is released. For instance, Dominguez [15] reports that the largest exchange rate jumps occurs within 10 seconds after a macroeconomic announcement.

This literature has additionally investigated the strength of the link between news and exchange rate prices of different macroeconomic announcements and where (country) are they coming from. For instance, Evans and Speight [11] report the dominance of US announcements in impacting EUR-USD volatility and the importance of Employment Report released and US Trade Balance features in line with previous studies [8, 9, 14] suggest that news regarding real variables is more influential than news regarding nominal variables and that announcements timing matters as exchange markets react to those released earlier because later announcements are to some extent redundant or, to put it in other way, the former announcements anticipate to market agents the latter ones.

Within this empirical context, this paper revisits this topic but from a different perspective. By quantifying worldwide economic calendar announcement news in several recent years we were able to construct a long time series with the objective to test whether it influence exchange rate 
movements of several currencies. In order to do that, Granger causality test was employed by using a computational approach. Our results show that announcements from U.S.A are, by far, the most important influence over the three rates considered, Euro/Dollar, Euro/Yen and Dollar/Yen. The method proposed here opens the door to address several open questions until now.

The rest of the paper is organized as follows. Next section explains the employed methodology including the way in which news' impacts are quantified. Section 3 presents our main results and, finally, section fourth concludes.

\section{Methodology}

\section{Exchange rates}

Three spot high frequency intraday exchange rates have been used in this work, Euro/Dollar, Dollar/Yen and Euro/Yen, which will be denominate generically as forex $(F x)$. Historical data were downloaded from Livecharts (www.livecharts.uk.com). Each data set is made up of oneminute observations for a period of 5 years, starting at January 1, 2008 and ending at December 31, 2012. Periods without trading activity (weekends) were excluded. Fx returns were calculated as

$$
r(k)=\frac{F x(k+1)-F x(k)}{F x(k)}
$$

Volatility from returns was then calculated in order to best characterize time fluctuations in exchange rates. As we will see below the minimum interval, $\mathrm{D}$, between news announcements will be set in ten minutes, so exchange rates volatility will be calculated in that temporal interval,

$$
\operatorname{vol}_{\Delta}(i)=\frac{1}{\Delta} \sum_{k=1}^{\Delta}|r(k+i)|
$$

In this way, around $37.870 F x$ observations/year will be used in the analysis. Fig. 1 displays Euro/Dollar quotes for the year 2012 (upper panel) and the corresponding returns volatility, calculated by using Eqs. 1 and 2 (lower panel).

\section{News impact quantification}

Perhaps the most important step in assessing whether macroeconomic information affects or not exchange rate movements is in the news quantification process. In order to do that data from the world economic calendar of an internet provider, Investing.com (www.investing.com) was used. In that calendar, news announcement from more than 70 countries all around the world is supplied.

Macroeconomic news encompasses several categories such as employment information, economic activity, confidence indices, central banks announcements, balances, etc. Each event is composed of: time of announcement, currency from the country source, announcement importance, the event itself, the released value, the forecasted value and the previous value. In many cases, however, events are reported as meeting minutes, central banks speak information, etc. without numerical values. We have disregarded all of these, although important, information, in order to obtain numerical time series.

\section{Eur/USD (Rate)}

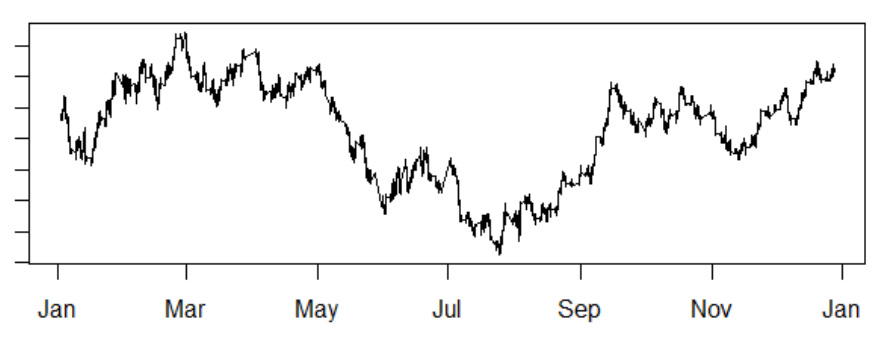

Eur/USD (Volatility)

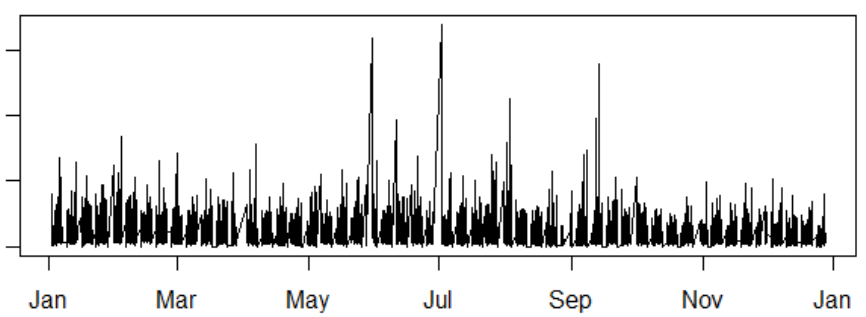

Fig. 1. Representative spot exchange rate (Euro/Dollar) time series for year 2012. Upper panel shows Eur/USD exchange rate. Lower panel shows Eur/USD returns volatility, as calculated accordingly with Eq. 2.

In constructing the news announcement time series several steps were performed in order to quantify the impact of macroeconomic news, namely:

1) Country importance $(C I)$ : we have weighted the importance of a particular announcement accordingly with the source country or region GDP. Somehow arbitrary we have assigned a weight of 10 to both European Union (EU) [16] and U.S.A. economies, 8 to China and Japan, 6 to Germany and France, 4 to Brazil and United Kingdom, and so on up to 1 for every other economy.

2) Announcement importance $(A I)$ : several types of announcements are more important than others. We have divided in three categories the kind of announcements, ranging from 1 to 3 , assigning a weight equal to 3 to those more important announcements (as for example the country Consumer Price Index ) events

3) There exist several types of announcements such that positive values implies however a "bearish" sentiment in the corresponding economy, for instance "Initial Jobless Claims" in U.S. In those cases we have simply reversed the sign of the announcement.

4) Time of the announcement release: Announcement release can be done at any time, even during weekends. Thus, we have modified the time order of announcement in the following way. The minimum time interval considered was ten minutes, thus, any announcement released in between multiples of 10 minutes $(10,20,30,40,50$ and 60$)$ has been moved to the following 10 minutes mark. Moreover, those announcement released during the weekend were moved to the first forex trading time of the week (21:00 GMT Sunday). 
American news

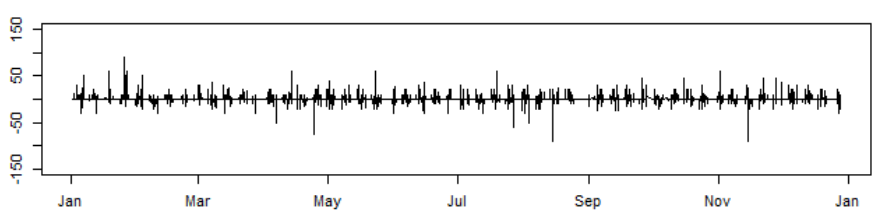

Asian news

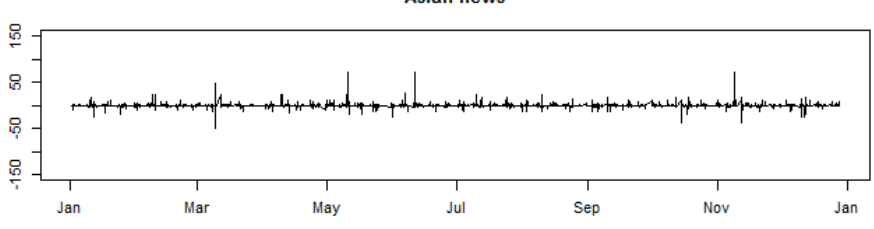

European news

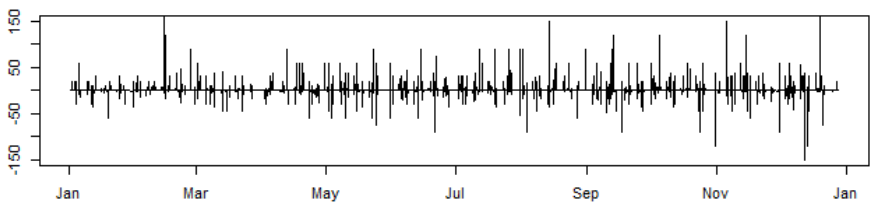

Fig. 2: Announcements news (year 2012) quantification, as explained in the Section Methods, for the America (upper panel), Asian (middle panel) and European (lower panel) regions.

Impact of news announcements was then quantified by simply multiplying the weights estimated in points 1) and 2) with the return of the released value (expressed as a percentage),

$$
\text { impact }=100 \times \frac{(\text { actual }- \text { previous })}{\text { previous }} \times C I \times A I
$$

Illustrative quantification of news announcements accordingly with the above assumptions is displayed in Fig. 2 for American, Asian and European areas during the year 2012. Total number of correctly quantified news for each region and year are summarized in Table 1.

Table 1: Number of quantified news classified accordingly with region and year.

\begin{tabular}{lllll}
\hline Year & America & Europe & Asia & Total \\
\hline $\mathbf{2 0 0 8}$ & 837 & 989 & 654 & 2480 \\
$\mathbf{2 0 0 9}$ & 1111 & 1220 & 807 & 3138 \\
$\mathbf{2 0 1 0}$ & 1337 & 1390 & 915 & 3642 \\
$\mathbf{2 0 1 1}$ & 1773 & 1595 & 1310 & 4678 \\
$\mathbf{2 0 1 2}$ & 2371 & 2956 & 1769 & 7096 \\
\hline
\end{tabular}

\section{Granger Causality}

Based upon N. Wiener ideas [17], Granger implemented [18] a procedure to test whether a causal relationship between two time series exists or not, formulated in the context of linear auto-regressive models [19]. Given two time series $\mathbf{x}=x_{k}, k=1, N_{d a t}$ and $\mathbf{y}=y_{k}, k=1, N_{d a t}$, the Granger Causality (GC) basically examine whether futures values of $\mathbf{x}$ are better predicted by using past values of $\mathbf{y}$, instead of using exclusively past values of $\mathbf{x}$. If this is true, we may say that $\mathbf{y}$ Granger cause $\mathbf{x}$. In order to numerically implement these ideas, the following procedure is performed. A linear auto-regressive model of order $L$ is fitted to each time series $\mathbf{x}$ and $\mathbf{y}$, with its corresponding parameters $a_{i}$ (in $\mathbf{x}$ ) and $b_{i}$ (in $\mathbf{y}$ ) and standard errors $e_{x}$ and $e_{y}$ such that

$$
\begin{aligned}
& x_{k}=\sum_{i=1}^{L} a_{i} x_{k-i}+\varepsilon_{x} \\
& x_{k}=\sum_{i=1}^{L} a_{i} x_{k-i}+\varepsilon_{x}+\sum_{i=1}^{L} b_{i} y_{k-i}+\varepsilon_{y}
\end{aligned}
$$

If the second prediction is better than the first one, we may say that past values of $\mathbf{y}$ influence present values of $\mathbf{x}$. To quantify "better" in a statistical sense, a comparison between $e_{x}$ and $e_{y}$ is performed, for instance by using,

$$
F_{y \rightarrow x}=\ln \frac{\operatorname{var}\left(\varepsilon_{x}\right)}{\operatorname{var}\left(\varepsilon_{y}\right)}
$$

Such that $F_{y \rightarrow x}$ is non-negative and as greater $F_{y \rightarrow x}$ is, better is the fit of the combined model, thus implying a causality from $\mathbf{y}$ to $\mathbf{x}$. Statistical significance of this equation can be assessed by using the Fisher test

$$
F_{y \rightarrow x}=\frac{\frac{R S S_{x}-R S S_{y}}{L}}{\frac{R S S_{y}}{N_{d a t}-2 L-1}}
$$

Where $R S S_{x}$ and $R S S_{y}$ are the residual sum of squares of models $\mathbf{x}$ and $\mathbf{y}$, respectively.

In our particular case both time series $\mathbf{x}$ and $\mathbf{y}$ will be replaced by exchange rate volatilities (Eq. 2) as one the time series and announcement news time series as the other time series.

\section{Surrogate data}

Although GC test performs suitably well at the time to assess causality issues, we have nonetheless compared our results against surrogate data. In order to do that several sets of announcements news time series have been generated such that announcements release times have been randomly shuffled, that is, the number and characteristics (country/importance) of news for each year/region have been preserved but its time position have been moved at random to other, different, time position in the same year/region. In this way we can generate a set of surrogate announcements news to compare, by using GC, with exchange rates time series.

\section{Results}

Fig. 3 displays our main results. In that figure we have plotted Eq. 5 for several model orders (Eq. 4), from $L=1$ up to $L=10$. We have calculated GC for every year since 2008 to 2012 between each of the three exchange rates, Euro/Dollar, Dollar/Yen and Euro/Yen, and news from America, Asia and Europe. In each case GC was calculated 
in both directions, that is, News $->$ forex and forex $->$ News. We have plotted only significant values (Eq. 6) up to 0.01 level. For instance, the upper and left panel shows results for the year 2012 in the Euro/Dollar exchange rate. The intensity of GC between this exchange rate and news from the three considered areas, Asian (AsNews), European (EuNews) and the American (AmNews) news is displayed in a gray code, accordingly with the right bar. As stated in the Methodology section (news quantification), time was discretized with a minimum resolution of 10 minutes, for both exchange rates and news. Model order is therefore expressed in that time resolution. For instance, a model order of three, $L=3$, means that the fitted autoregressive model extend to the past $30(3 \times 10)$ minutes. As can be clearly seen in that upper-left panel, news from America seems to influence significantly the Euro/Dollar dynamics, especially at short intervals, with a maximum at the ten subsequent minutes of the announcement release. Also, although with much less intensity, news from Asia seems to also affect Euro/Dollar dynamics. The effect of American news over Euro/Dollar exchange rate is clearly seen in all the analyzed years, with a maximum of intensity during 2012 and minimum intensity during 2009. Moreover, it seems that announcements from America not only influence the Euro/Dollar exchange, but also the other rates, Dollar/Yen and Euro/Dollar. Finally, the effect of American news seems to increase from 2008 on.

On the other side, news announcements from Europe do not have practically any impact in either Dollar/Yen or Euro/Yen rates.

During 2008 Asian news affect moderately Dollar/Yen and Euro/Yen, a fact which however does not repeat in the subsequent years until 2012. In this year it seems that news announcements from Asia become more relevant, at least in the Euro/Yen and Euro/Dollar rates.

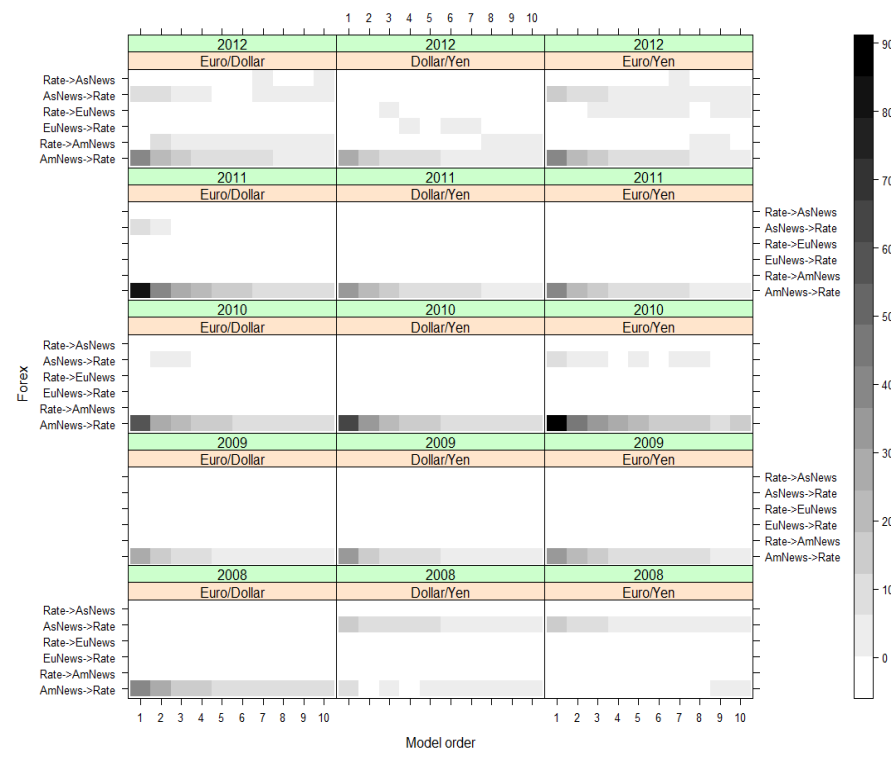

Fig. 3: Granger test between exchange rates and actual announcements news. Only significant values (Eq. 6) at 0.01 confidence level have been plotted. Model order ( $L$ in Eq. 4$)$ is displayed in the horizontal line. Both directions, Exchange rate $->$ News and News $->$ Exchange rates are displayed in the vertical line, for every year, Exchange rate and news region. See main text for further explanations.

Conversely, it seems that, at least in some cases, a reverse influence also take place. For instance during 2012 the Euro/Dollar forex appears to GC American News, a fact which is certainly impossible for such short times. In order to cope with these spurious indications of causality we have implemented a surrogate scheme, as explained in the section methods, in order to evaluate whether causality relations between forex time series and actual news announcements time series are statistically significant. To do that, we have destroyed any possible causal relations between pairs of time series in the following way. While Forex time series remained unchanged, news announcements time series were modified by randomly shuffling the time order of announcements events. In this way new announcements time series were generated with the same number and importance of the original ones. We have generated fifty surrogate sets of announcements time series with this methodology. In every case, GC between surrogate time series and forex was calculated, thus obtaining results as the ones displayed in Fig. 3.

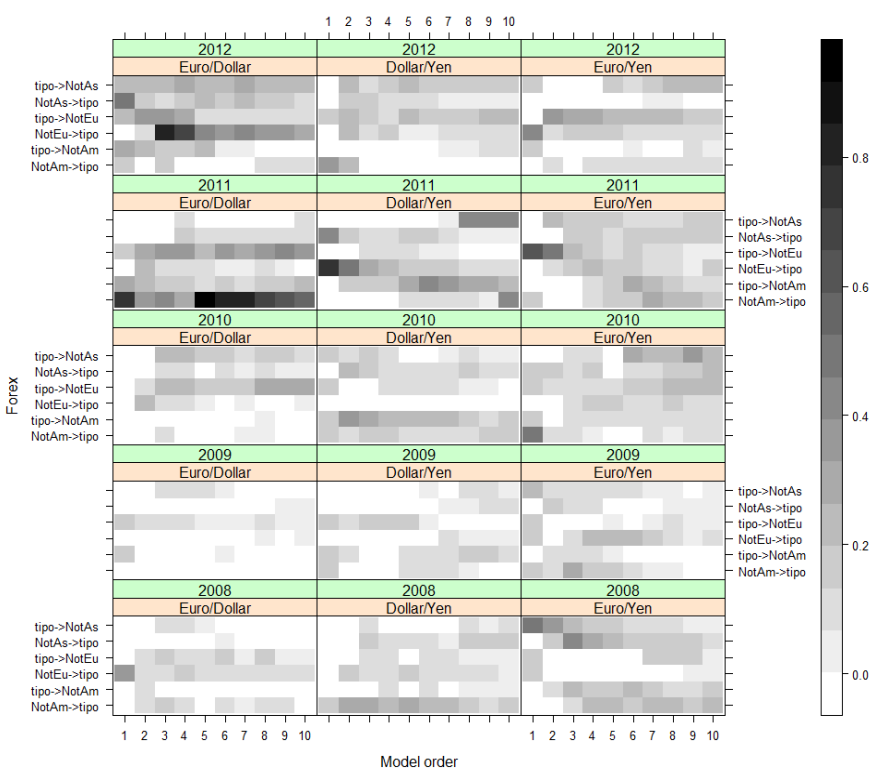

Fig. 4: Granger test between exchange rates and surrogate announcements news. Only significant values (Eq. 6) at 0.01 confidence level have been plotted. Model order ( $L$ in Eq. 4$)$ is displayed in the horizontal line. Both directions, Exchange rate $->$ News and News -> Exchange rates are displayed in the vertical line, for every year, Exchange rate and news region. See main text for further explanations.

Fig. 4 display averages of GC, Eq. 5, between original forex time series and surrogate announcements time series. Besides the qualitative difference between this figure and Fig. 3, it is striking the quantitative difference between both figures. Whereas in Fig. 3 maxima values are around 80/90, GC between forex time series and surrogate announcements time series are below 1. Moreover, there is no apparent difference between causality in one or the reverse direction a fact which support the robustness of Fig. 3.

\section{Conclusions}

In the present work we have introduced a novel methodology to investigate whether and to what extent, forex quotes were driven by news announcements of world macroeconomic situation. Impact of macroeconomic information was quantified by using ad hoc rationale assumptions over the world economic calendar announcements, in the period 2008-2012, yielding more than 20.000 events. To test the methodology, returns' volatility, calculated at 10 minutes intervals, of three exchange rates were used, Euro/Dollar, Euro/Yen and Dollar/Yen (around 568.000 observations). Classical Granger causality in both 
directions was then calculated between forex and news announcements time series.

Although considerable time fluctuations exists along the whole analysed period (2008-2012), our results clearly support a direct effect of news announcements over exchange rates markets in line with previous studies such as in references $[1,7,9,11]$. This fact is predominant when news came from America [9, 11], although as a novelty some influence from Asian news is becoming important in the last years.

Our findings should be interpreted as a first and very simplified approximation of the underlying methodology presented here. Traditional GC is a linear method and, as it is well known in the empirical literature [20, 21], the assumption of linear dependence is actually violated in many situations. Although a non-linear dependence can be approximated by a linear regime especially at very short times as in the present case, a complete analysis should encompass both linear and non-linear GC methods. Also, quantification of news impacts, as presented in the methodology section should certainly be explored and redefined in several directions. More involved analysis are currently undertaken, as for instances detection of asymmetries regarding the arrival of positive and negatives news and will be published elsewhere.

\section{References}

[1]. G. Galati and C. Ho, Economic notes by banca monte dei paschi di siena spa 32(3), 371 (2003).

[2]. R. Meese and K. Rogoff, Journal of International Economics 14, 3 (1983)

[3]. N.C. Mark, American Economic Review 85, 201 (1995).

[4]. J. Frenkel, Journal of Political Economy 89(4), 665 (1981).

[5]. S. Edwards, Economics Letters 9, 377 (1982).

[6]. E.J. Bomhoff and P. Korteweg, Journal of Monetary Economics 11, 169(1983).

[7]. C.A.E. Goodhart, S.G. Hall, S.G.B. Henry and B. Pesaran, Journal of Applied Econometrics 7, 199 (1993).

[8]. R. Payne, Working Paper, London School of Economics (1996).

[9]. T.G. Andersen and T. Bollerslev, Journal of Finance 53, 219 (1998).

[10]. T.G. Andersen, T. Bollerslev, F.X. Diebold and P. Labys, Journal of the American Statistical Association 94, 42 (2001).

[11]. K Evans and A. Speight, Journal of the Japanese and international economies 24, 552 (2010).

[12]. R.N. Mantegna and H.E. Stanley. An introduction to econophysics. Cambridge University Press (2000).

[13]. A. Almeida, C. Goodhart, and R. Payne, Journal of Financial and Quantitative Analysis 33, 383 (1998).

[14]. T. Andersen, T. Bollerslev, F. Diebold and G. Vega, American Economic Review 93, 38 (2003).

[15]. K.M. Dominguez, NBER Working Paper 7337 (1999).

[16]. EU was considered as a single economy and ranked according with its GDP in the first place (with USA). Considering both the macroeconomic information coming from the EU and those from its member countries, especially Germany and France, would sound redundant and to some extent contradictory. As a first approximation, we have included nonetheless all the available information in this work. More refined analysis discriminating this apparent redundancy is now under way.

[17]. N. Wiener, The theory of prediction. In: Beckenbach, E. (Ed.), Modern Mathematics for Engineers. McGraw-Hill, New York (1956).

[18]. C. Granger, Econometrica 37, 424 (1969).

[19]. S. Bressler and A.K. Seth, Neuroimage 58(2), 323 (2011).

[20]. C. Hiemstra and J. D. Jones. The Journal of Finance 49(5), 1639 (1994).

[21]. I. Asimakopoulos, D. Ayling, and W. Mansor Mahmood. Economics Letters 68(1), 25 (2000). 